\title{
Learning and innovation in agriculture and rural development: the use of the concepts of boundary work and boundary objects
}

Talis Tisenkopfs, Ilona Kunda, Sandra šūmane, Gianluca Brunori, Laurens Klerkx \& Heidrun Moschitz

\section{Introduction}

Innovation processes are increasingly conceptualized as the outcome of collaborative networks where information is exchanged and learning processes happen (Knickel et al. 2009, 139). The SOLINSA project explored learning and innovation in specific kinds of networks - LINSA, defined as Learning and Innovation Networks for Sustainable Agriculture, which involve actors who are mutually engaged to achieve common goals for sustainable agriculture and rural development by cooperating, sharing resources and co-producing new knowledge (Brunori et al. 2013). LINSA represent learning and innovation in heterogeneous multi-actor environments as they consist of actors from different agrofood domains: producers, consumers, experts, NGOs, SMEs, local administrations and components of the formal AKS. Taking into account such diversity of actors and their dispositions, multi-actor interactions and co-construction of new shared meanings are central components in learning and innovation in LINSA.

In order to better understand and facilitate agricultural learning and innovation in multi-actor networks we need to examine mechanisms that allow their joint endeavours, connections between diverse lifeworlds and knowledge bases. The idea increasingly applied to examine such processes is that of boundary work and its components, boundary objects among these. Boundary work helps to manage all kind of demarcations between and within different actors and social groups and align their different motivations, perceptions and expectations into common cognitive frames and concerted actions (Clark et al. 2011; Klerkx, Van Mierlo, and Leeuwis 2012). Thus it is important to gain insight into how boundary work manifests itself in different contexts and what makes it effective.

We go beyond the original tradition of science and technology studies which view boundary work as an element of communication and knowledge transfer between science and non-science (Gieryn 1983; Moore 1996; Guston 2001) and look at interactions within a more diverse set of actors, notably at interactions among practitioners themselves, peer-to-peer relations, involvement of civic groups, local administrations, etc. We use the concept of boundary work to highlight exchange and translation of individual knowledge stocks into collectively shared, durable knowledge and innovations for sustainable agriculture, which go hand in hand with the development of networks themselves.

In particular we analyse the processes and outcomes of boundary work in connecting and aligning LINSA actors across different social, institutional and conceptual boundaries in the three key domains of LINSA: joint learning, innovation and negotiating agricultural sustainability. These three domains are closely interrelated but each of them also illuminates a different aspect and an intervention area of boundary work. Boundary work in learning is primarily about construction of common cognitive frames: alignment of ideas, perceptions, interpretations, meanings. Boundary work in innovation is more focused on joint action formation or alignment in practices. Boundary work regarding sustainability demonstrates both cognitive and practical alignment in such a highly contested arena as sustainability is, and which may 
demand particular efforts from multi-stakeholder networks to develop and implement shared holistic solutions. In addition, in all three domains we analyse boundary work and objects in a dynamic perspective and capture their changing purpose, form, scope and outcome along the life-span of networks. A longitudinal collaborative research with LINSA allowed us to observe and analyse the evolution of boundary work and objects.

The article has four sections. The first section provides theoretical input to conceptualize boundary work and boundary objects. The second section characterises cases and outlines the methods used to analyse boundary work. The third section explores the manifestations of boundary work and boundary objects to promote processes and outcomes on learning, innovation and sustainability in LINSA. The fourth section reflects on the theoretical and practical implications of our findings with the view of helping LINSA to perform boundary work more efficiently.

\section{Conceptual framework to study boundary work and boundary objects in LINSA}

Following recent concepts of innovation as a systemic activity (e.g. Knickel et al. 2009; Klerkx, van Mierlo, and Leeuwis 2012) SOLINSA research addressed agricultural learning and innovation from a network approach which allows acknowledgement and integration of various knowledge actors, sources, types, and processes and learning modes. Thus, we shift from monoculture of scientific knowledge towards ecology of knowledge, which assumes the diversity of knowledge and its composite character (Santos, Nunes, and Meneses 2007; Bruckmeier and Tovey 2008). It allows considering farmers, but also consumers, rural residents, market enterprises, NGOs, policy makers and other actors with their diverse knowledge inputs to agricultural development (Knickel et al. 2009; Oreszczyn, Lane, and Carr 2010; Leeuwis and Aarts 2011; Renting et al. 2008). The network model advocates active social learning (Wenger 2000; Leeuwis and Aarts 2011), which stresses that knowledge is contextually grounded and acquired in interaction and negotiation between actors. To achieve learning and innovation in hybrid networks, actors have to align their diverse attitudes, motivations and values into a shared knowledge pool and collective or concerted action. This is of particular relevance regarding the highly contested concept and practices of sustainable agriculture (Koutsouris 2008; Hermans et al. 2010).

It has become acknowledged that building and managing learning and innovation in multi-stakeholder networks requires boundary work that would improve connections of different life-worlds, facilitate learning across their boundaries and transformation of knowledge into innovation (Klerkx and Leeuwis 2009; Clark et al. 2011; Klerkx, Van Mierlo, and Leeuwis 2012; Mollinga 2010). Boundary work is needed because tensions arise at the interface between actors with different views of what constitutes reliable or useful knowledge (Clark et al. 2011). Diversity and conflicts present in such networks can be enriching and facilitate creativity and innovation, but they can also block up new ideas and initiatives if common interest and language among actors cannot be established (Ring, Peredo, and Chrisman 2010). Communication failures are frequent when differences in objectives, interests, languages, frames are wide and no interfaces between them are found. This calls for management or enabling of knowledge processes across boundaries, i.e., boundary work.

In exploring boundary work, there are some shared hypotheses on what promotes its success, namely meaningful participation of stakeholders in agenda setting and knowledge production, accountability of governance, and the use of boundary objects (Clark et al 2011). However there is a shortage of analysis 
of successful strategies in particular settings (ibid). Our study contributes to exploring boundary work and its outcomes, focussing on "multiple heterogeneous communities of knowledge producers" (ibid; 2) which are inside or outside LINSA - self-governing entities in sustainable agriculture, with a considerable component of learning and innovation in their activities. It is a distinctive setting, which has been explored very little so far, thus our study aims to identify some distinctive traits in boundary work strategies and outcomes.

We target the participation processes and boundary objects used in boundary work, and aim to view the kinds of interactions used to foster connections between agents, constellations of agents that participate, and outcomes achieved - for the three LINSA activity domains and the network on the whole.

To characterise the boundary work interactions, we use as the starting point ideas from Wenger (2000; 236-237), who distinguishes between four types:

- encounters - visits, meetings, and in short anything providing exposure to a different practice;

- boundary practice - a special practice aimed at maintaining the crossing of boundaries;

- peripheries - practices to allow connecting for interested outsiders or potential members;

- specific tasks/projects - kinds of practice that result from addressing non-routine topics, bringing together novel kinds of participants and transforming roles.

We aim to see the peculiarities of these interactions in the multi-stakeholder, evolving context of LINSA, thus linking it also to the issue of participants, i.e. uncovering typical constellations of agents.

Certainly the interactions are aimed to produce specific outcomes, which for LINSA are related to learning, innovation, negotiation of sustainability and the network development as such. We will expand on these when discussing boundary objects, a third important component of boundary work, which brings together boundary work interactions and their participants.

A boundary object is defined as "an entity shared by several different communities but viewed or used differently by each of them, being both plastic enough to adapt to local needs and the constraints of the several parties employing them, yet robust enough to maintain a common identity across sites" (Star and Griesemer 1989: 393). These are tangible or intangible - a trademark, a publication, a code of practice, a website, a strategic paper, an idea etc. - and are of shared interest for participants and therefore create interfaces for their communication, interaction and coherence (ibid).

Boundary objects cannot be imposed; they emerge through the process of interaction (Star and Griesemer 1989: 393); the process of joint development of a boundary object fosters interaction through verbal and non-verbal communication.

A very general categorisation of boundary objects (Wenger 2000) is that of artefacts, discourses and processes. For our purposes, it is important to identify typical manifestations of various categories of boundary objects in LINSA, as well as their evolution.

With regard to LINSA activity domains, it is important that the key feature of boundary objects is their interpretative flexibility which allows actors to find their own meaning in them, thus furthering learning through discussion with other actors of the different interpretations (Klerkx, van Mierlo, and Leeuwis 2012). For instance, boundary objects can help to align different frames in issue specific learning (Tisenkopfs, Kunda, and Šūmane 2014). 
Boundary objects also act as vehicles for change by enabling networks of actors to align around a certain vision they espouse, negotiate a shared direction, and enhance collaboration in innovation processes (Klerkx et al. 2012). Similarly Guston (2001: 400) notes that boundary objects may change practices on both sides of a boundary, although this requires consent of agents and perhaps broader cultural changes.

Movement toward change may be made more evident by distinguishing between general and specific boundary objects. A general boundary object is about 'ground rules' and is created in early stages of managing of a boundary, while specific boundary objects are created to deal with more fine-tuned, context-specific issues. There is a certain evolution of boundary objects and boundary work, which also links boundary work to network development (from early to more evolved stages, as more complex boundary work is carried out and achieves goals).

Thus boundary work is related to certain outcomes for interaction participants and the whole network. We will explore these outcomes in learning, innovation, negotiation of sustainability and network development in LINSA.

\section{Cases and method}

In order to explore boundary work in agricultural learning and innovation networks we chose six of 17 SOLINSA cases which provide diverse empirical evidence of boundary work. The following selection criteria were used: 1) the intensity and types of the boundary; 2) the diversity of actors involved; 3 ) the variety of boundary objects; and 4) outcomes of boundary work in terms of contribution to learning, innovation and sustainability.

The cases were grouped according to the main focus of boundary work - learning, innovation, sustainability - and each dimension was represented by two cases in order to characterise variations. Importantly, boundary work and objects have multiple and combined impacts on learning, innovation and sustainability processes and outcomes; however, for analytical purposes, we illustrate their contributions to a single most notable domain in a given LINSA. Evolution of boundary objects and boundary work was observed and examined during a two year period of researchers' collaboration with LINSA stakeholders as a part of action research. Empirical data is derived from SOLINSA case studies, comparative reports and specific descriptions of boundary work and boundary objects that were produced for each LINSA. In the Table 1 we provide an overview of boundary work manifestations in the examined LINSA.

[Table 1. Boundary work manifestations in LINSA depending on boundary work focus]

The selected cases represent agricultural networks of varied origin, size, stakeholder diversity, objectives of innovation, and approaches to sustainability from agriculturally focussed to holistic ones. They are related to different areas of agriculture, food production and consumption, rural development and involve new urban-rural linkages. The analysed networks represent intensive learning processes and cross-linkages between different domains of knowledge. The innovations are often a combination of technical, economic, organisational, social and political innovation and sustainability concerns are explicit in all networks, however in some LINSA not clearly agreed. A broad range of learning and innovation needs, structural differences in the networks, various knowledge bases and interpretations of action call for negotiation of meanings, reconciliation of interests and alignment of practices. The selected cases show that boundary work and objects may effectively bridge social, cognitive, ideological, 
emotional, political, and technical boundaries within the networks, between LINSA and external environment, or propose a new space for innovation with redefined former boundaries, roles and identities.

\section{Using boundary work and objects in LINSA to enhance learning, innovation and sustainability}

In this section we analyse how boundary work takes place in networks in specific domains of learning, innovation and sustainability, what are the typical boundary interactions, participant constellations and boundary objects used.

\section{Boundary work for learning}

For active and relevant learning to occur, the network participants have to negotiate a number of boundaries, between various 1) stakeholder groups representing various knowledge bases (e.g. farmers, researchers, advisors); 2) learning issues (technical, economic, organisational, political) as they may change during the course of innovation; 3) learning forms (e.g. face-to-face and technically mediated); and 4) attitudes towards learning outcomes, mistakes and difficulties. This means that boundary work has to be carried out to maximise the resources present in the network and stimulate the learning necessary to achieve the network's goals. Boundary work would include various interactions to align network participants' needs, expectations, perceptions and practices, to allow new knowledge to be developed. Two cases demonstrate how boundary work and boundary objects enhance learning in complex agricultural networks.

The Latvian Fruit growing network consists of diverse actors ranging from orchard owners, farmers' associations, cooperatives, research institutes, public organisations, retailers and consumers engaged with ideas and practices of integrated fruit-growing. The network is aimed at development of fruit growing sector in Latvia and promotion of the market of local fruit. It is geographically spread across the country and has several territorial sub-networks of more intensive learning and innovation.

Learning in the LINSA unfolds in several interrelated directions: fruit-growing technologies, economic organization of supply chain, use of state support, education of consumers. In the recent years with the development of new orchards and the establishment of producer groups, learning intensifies into the economic domain and relates to organization of collective marketing, sales, branding, developing the links with consumers.

Boundary interactions around these issues are intense and involve various stakeholders in different combinations. Learning about agricultural policies happens in interaction between farmers' organizations and policy makers; new methods in horticulture are learnt in mutual exchange among farmers and between the farmers and researchers; knowledge about processing is acquired from food technologists and experienced producers; marketing knowledge is generated in farmers' interaction with retailers and cooperatives.

The Fruit LINSA demonstrates the presence of three kinds of boundary work: encounters, peripheries and specific work. Encounters (field days, study tours, demonstrations, seminars, individual consultations) are a particularly effective form of boundary work as they bring together farmers and researchers in direct face to face learning situation. This form was found most widely used in LINSA for 
technical learning issues (growing technologies, varieties, plant protection, etc.). This form of boundary work is highly praised by the farmers as it provides hands on experiential learning and is also emotional. Projects implemented by research institutes (applied research and demonstration projects) and cooperatives (investment projects) are manifestations of special boundary work which allows to undertake systematic learning activities (educational seminars, training courses, study visits abroad, farmers commissioned researches etc.) over a longer period of time. Many boundary work activities in fruit network are technically mediated (e.g. information retrieval and Q\&A sections on websites of research institutes and farmers' organisations, web based training courses, remote service provision for farmers using internet and SMS) and become available to farmers due to expansion of internet based knowledge services and enhancement of farmers computer skills.

Integrated fruit growing is a general boundary object whose various aspects - growing technology, processing methods, marketing infrastructure, supportive public policy, consumers demand - are explored, discussed and redefined in the network's interactions. Different more specific boundary objects are generated in sequence corresponding to the learning needs of individual members and to the overall evolution of the network. In the initial phase of LINSA development when the orchards were planted, appropriate apple varieties and cultivation techniques were specific boundary objects discussed among farmers and researchers. When the production became more established the marketing issues became topical and the network members interacted around boundary objects such as marketing infrastructure, storage facility, cooperative sales, contracts with retailers, etc. The Fruit network is peculiar as it develops and actively uses culturally attuned boundary objects - festivals and public events (e.g. Apple Festival, Cherry Days, Scientists night) to connect with the wider public and promote consumer education about fruit sector and sustainable food production and consumption issues. In a hybrid network, specific boundary objects may be activated in specific bilateral or multilateral interaction, e.g. quality standards and kinds of apple varieties are a notable boundary object in negotiations with retailers; while crown shaping techniques are negotiated in consultations and field days between researchers/consultants and farmers.

Thus, boundary interaction enhances both learning processes and role changes - researchers become consultants, farmers co-innovate with researchers, some consumers start gardening, children become educated about sustainable diets through School Fruit programme, etc.

Inclusive boundary work and objects enhance participation in the network and makes it more egalitarian, especially enhancing learning in the network peripheries (Lave and Wenger 1991). However, boundary work does not happen by itself, the leading personalities or organisations (boundary brokers) are needed. In the Fruit LINSA the driving actors for boundary work are fruit researchers committed to knowledge sharing, the leaders of producers' groups, and individual farmers who are open to share their experiences with peers. This 'triangulation' between the researchers, farmers' organisations and individual farmers open for knowledge exchange makes boundary work effective and helps to bridge the traditional research-practice gap.

The Charter of Good Practices is a French network of farmers, farmers' organizations, research and extension organizations built as a collective answer to the mad cow disease crisis. The idea was to foster the quality and the security of cattle farmers' practices and to communicate these to the beef and dairy industry, the retailers, and the general public. The task was two-fold: to formulate the principles of improved cattle-farming, and get a critical mass of farmers to implement them. 
The initiative was started by farmer organizations. They established a coalition with institutions of formal agricultural knowledge system which took a leading role in network building. Development of the Charter was a multi-level and multi-actor process bringing together all the stakeholders related to milk and beef production and consumption: the dairy and beef industry, retailers, consumer and citizen associations, regulation makers. To reconcile all the interests and concerns, a complex boundary work was carried out in the form of stakeholder meetings, development and implementation of farmers' and their advisors' assessment system. It was accompanied by technical work, expert consultations and, finally, synthesis, negotiation and decision making regarding the practice-generated issues.

Most of the boundary work was made through the involvement of the advisers who presented the Charter to the farmers and proposed them to evaluate their practices and to adhere to the Charter. A state funding of the facilitation and advisory activities positively influenced the farmers learning and adoption of new practices. Nowadays the network involves about 110000 farmers and 3000 facilitators and about $90 \%$ of the dairy farmers and $66 \%$ of the beef farmers in France belong to the Charter.

The main boundary object in this case is the Charter itself: a 12 pages leaflet, describing the 41 good practices the farmers commit to follow. Both for network internal and external use the Charter is made available on website and leaflets and logos are used as boundary objects to communicate with external actors. The Charter is periodically renewed in consultations among the stakeholders and improved descriptions of practices are made available to farmers through website and advisory work. Thus continuous boundary work results in updating of boundary objects. However, not all farmers, especially small and isolated ones, are involved in these boundary interactions due to the fact that they are not clients of the advisory organisation.

This case demonstrates the role of research and extension organizations in boundary work and rather top down manner of its organization. Partly this explains the scale of the network. Extensive boundary work was necessary to negotiate the Charter in the beginning and introduce novelties at later stages. The boundary work enhanced learning among farmers and changes in their practices and resulted in gradual changes within the whole cattle farming system. The example demonstrates how wellcoordinated boundary work activates learning, adoption of new practices and changing a regime.

Both cases suggest that the idea and practices of boundary work and objects illustrate the dynamic of learning - from unfamiliarity and lack of negotiated joint meaning to increased commonality through intensive negotiation of meaning (the object of negotiation being a boundary object at this point) to gradually arriving at a similar level of familiarity, agreed definition of what the object means and how to deal with it (at this point the boundary object becomes part of a shared practice). Another way to look at boundary work is to view it as a process of jointly filling up an empty knowledge space with jointly created knowledge, e.g. a new practice, a method being a boundary object. To sum up, we argue that boundary work co-evolves with the learning priorities and development of the network; boundary objects drive the flow of the learning and innovation and there might be a hierarchy and/or sequence in boundary objects produced. The role of leading boundary work organisations and persons was notable in both cases as well as purposeful use of boundary work and objects in peer-to-peer communication and external communication of the networks to introduce sustainable practices to other food chain actors, notably consumers.

\section{Boundary work for innovation}

Boundary work is instrumental for innovation development in LINSA and the creation of its support network. Establishing connections through boundary work can help even radical innovations spread 
actively and continue developing in new contexts, giving rise to satellite innovations. For that purpose the network needs mobilising new supporters, balancing the interest in economic gains and other values (social, ethical, knowledge development, etc.), and skills to negotiate expanded innovation goals. Thus boundary work may be needed with regard to 1 ) involving new stakeholders in the network to accept innovation, 2) gaining new supporters or users of the innovation outside of the network, as well as 3 ) adjusting the network goals to include new innovation goals, once the initial goal has been achieved, and/or new opportunities are identified. SOLINSA research identified the relevant boundary work processes and objects used to negotiate and promote innovation, and their impacts on LINSA. We illustrate it through two differing LINSA cases.

The case of the Dutch cooperative of health care farms "Boer en Zorg" demonstrates boundary work to promote a radical innovation both internally (within the LINSA) and externally (with public servants), the process in its turn influencing the development of the network itself. The innovation in question resides at the boundary of two knowledge worlds: agriculture and health. Care farmers use agricultural resources, such as landscape, animals, gardens, and forests to address the needs of people with health problems, reintegrate them into social and economic life and improve their wellbeing. Thus the development of innovation requires boundary work both to ensure its legitimacy and acceptance with policy actors and other relevant external stakeholders, and in parallel it has to gain new participants who implement the innovation and maintain a shared knowledge base among the existing ones.

In addressing the issues with external policy actors (on national and increasingly on local level) the LINSA makes use predominantly of encounters and special persuasion activities. The latter involve using and commissioning research to demonstrate the benefits of the innovation, to negotiate funding arrangements, and to lobby. Special work often takes the form of externally funded projects. Participants include LINSA activists and managers, researchers, and policy actors. The boundary objects are predominantly documents, but also concepts and ideas around the notion of care farming. With the prospect of more decentralisation in health care and increasing the role of local level government, the boundary work has shifted from general boundary object (what is the benefit of care farming) to very specific boundary object representing negotiated local level administrative and funding arrangements.

Internally, boundary work is required to ensure a shared standard of implementing the innovation, as care farming has its own certification. The LINSA includes several types of care farmers, differing in their backgrounds (agriculture, health care, other) and interest in developing the practice. Thus concerted boundary work is needed to negotiate these diverse knowledge bases and goals. The participants of boundary work are mostly LINSA members, with some external experts delivering specific information at training sessions. Another subset of participants is the accrediting institutions, which issue certificates to care farmers. The boundary work types are both encounters, practice-based (demonstrations, study visits) and special work (training sessions and courses). The outcome of the boundary work is prescriptive, as care farmers have to subscribe to certain standards of practice. The boundary objects in this strand of activities range from the concept of care farming and its components, acceptable practices, and most of these are documented in tangible form; there is also administrative software to be used by all. The evolution may be seen in further developing various standards of care farming activity to make implementation of the innovation both easier and of consistent quality.

With regard to impact on the network, the above development of the innovation has happened alongside with a search for appropriate governance form. The LINSA has grown in terms of members, clients and geographical coverage. Simultaneously, the rapid growth has put pressures on its cohesiveness which shows the need to balance external and internal boundary work and specifically the importance of internal one to establish shared understandings among LINSA members, facilitate their 
loyalty and engagement. Overall, the outcome of the external boundary work was successful institutionalisation of an innovative service at the boundary of two knowledge systems - agriculture and health care. It has contributed to the development of LINSA both in scope, shared meanings, and improved practices. Development of the LINSA has also meant dealing with new challenges, again requiring boundary work.

The case of the Italian Association Crisoperla is focussed on promoting a combination of economic and social innovation - organic farming and solidary economy in a specific region with previously scarce social interaction among farmers and citizens/consumers. The boundary work is targeting both external stakeholders - policy makers and the general public, and internal - farmers, fishermen, direct purchasing groups, citizen groups concerned with sustainable lifestyle issues. The distinctive trait of Crisoperla case is the involvement of the civic component, the ethical dimension of the innovation, and the ambition to spread its ideals as broadly as possible. Thus boundary work is very active and diverse.

In targeting the external stakeholders, the LINSA uses a considerable amount of special work organising public events, discussion forums, developing specific policy proposals, holding workshops in combination with farmers' markets. These involve not only farmers, but also activists from various civic groups, and entrepreneurs subscribing to solidarity economy ideals. Special work can be identified also in internal boundary work, namely in training activities, in carrying our research (e.g. on price formation of organic produce). Participants in this case are farmers, researchers, also activists. The special trait of boundary work in the Crisoperla case is the broad involvement of volunteers, and the driving role of several key individuals, linking organisations, civic groups, and economic entities. The boundary objects demonstrate a broad range, from concepts, ideas and principles (of solidarity economy and organic farming, but adapted to local conditions), to event programmes and public activities, as well as topics of learning and policy advocacy work, which would often turn into tangible objects (brochures, leaflets, etc.). Overall, the evolution of boundary objects can be traced from the earliest attempts to define the ideals of the LINSA as a code of practice, to very specific marketing and policy work arrangements, documents and artefacts embodying the network ideas. The outcomes of these activities can be termed concerted action.

The evolution of the network has been steady; successful boundary work has led to expansion of supporters and visibility, an increased range of participants, improved practices and increased impact on policies promoting the dissemination of the specific innovation (organic farming plus civic activities plus ethical entrepreneurship). In terms of network structures, this LINSA is characterised by regular and democratic decision making (monthly meetings, supplemented by virtual communication), owing much to the drive of some of the LINSA "founders". The challenges may be seen in perfecting the governance of the network.

In the above two cases we have demonstrated that boundary work can foster a range of outcomes related to innovation dissemination and evolvement, negotiating both internal and external boundaries with diverse stakeholders. The scope and targets of boundary activities derive from the specific context: in the case of Care farms network boundary work may be characterised as more specific, on a narrow range of issues, centred on technical knowledge. In the case of Crisoperla the range of boundary work is much broader and addresses social and ethical issues, aiming to link diverse actors who subscribe to similar values, while also negotiating specific technical issues. Much boundary work is related to network development as such. 
In both cases, the boundary objects are developed in the context of specific participants engaging in specific kinds of interaction, according to the goal of boundary work and the connections that have to be made or managed.

\section{Boundary work for sustainability}

SOLINSA research suggests that negotiation of the meaning of sustainability is a complicated endeavour, due to the diversity of LINSA members and also external messages from the general public and policy actors. Thus, to achieve better alignment on the meaning of sustainability or adjust it to relevant external developments, the following boundaries may have to be navigated: 1) between groups of LINSA stakeholders, 2) between LINSA and external civic groups, 3) between LINSA and policy actors and/or representatives of the existing regime. Boundary work on specific meanings of sustainability and evolvement of relevant boundary objects in LINSA are presented below in two cases.

The Brighton and Hove Food Partnership in England highlights the dynamic co-evolution and multiplicity of boundary work and objects in developing sustainable local food systems in an urban area. Started from the need and the desire of sustainable living in a holistic sense, the partnership aims at integrating urban food chain with sustainable actions in other related areas (waste, health, energy, transport) in order to ensure urban sustainability and well-being.

The Brighton and Hove City Council is one of the key driving and boundary work actors in establishing and operating the partnership. At the origin of the partnership there was the Council's action plan on food which can be categorized as a specific boundary object and which expressed the local state's willingness and readiness to promote sustainable food issues. There were other boundary events and objects set up in the city before the establishment of the partnership: a report and a conference on food which concluded on the need to establish an overarching body to encourage and coordinate a more sustainable food system.

The inclusive, holistic vision of sustainable urban development formed the seminal boundary object around which a group of driving actors consisting of representatives from local policy and civic groups were gathered. Subsequent boundary work to develop and implement this vision brought together and reconciled many individuals and networks with seemingly different functions and interests, but whose common values and beliefs were uncovered in collaborative work. Firstly boundary work happened at encounters with a broad range of civic and market actors involved. Then specific work by a task force followed - collaborative development of a proposal for the city policies and lobbying it. The boundary object evolved further to become a City Food Strategy. After adoption the Food Strategy still remained a boundary object as various stakeholders had to interpret it for implementing. Satellite initiatives developed, e.g. grants to practice urban gardening, which in themselves became boundary objects and which added another kind of boundary work - practice-based. Because of its holistic nature, the LINSA was also able to encourage other kindred networks to develop related sustainable systems (Curry and Kirwan 2014).

The holistic approach of the partnership means also that there are many diverse urban food actors involved in boundary interactions (there are 200 individual and collective members) and many other are targeted. In order to align their attitudes and practices active boundary work is present. The partnership itself functions as an interface for their interactions and a boundary breaker. The specific boundary objects it has produced, a booklet and a food strategy, outline the diversity of boundary work and objects used in the LINSA, which altogether are aimed at promoting sustainable living and connecting actors. They contain such general and specific items as a newsletter on food, health and environmental 
issues, a webpage, health and local food work, courses and programs to promote sustainable, healthy and active lifestyles, local produce festivals and other meetings and networking which bring together people from diverse sectors, production of an action plan and lobbying policies.

The boundary objects in this LINSA have evolved from the initial general vision, which later on was supplemented by more specific and practice oriented ones, all evolving over time. The range of participants is very broad and diverse, with civic groups and local policy makers dominating. Boundary work involves co-existing encounters, specific work and practice-based connections, all giving rise to implementing a shared transformative idea of sustainability, of a "breaking the mould" variety.

The most prominent sustainability outcome of boundary work in Brighton and Hove food partnership is the widely shared redefined understanding of sustainable well-being in the city and the changing food practices. The network is aiming at changing values and lifestyles, and its popularity among the citizenry shows that it is successful in disseminating its holistic vision of sustainability. The formal result of the collaborative work in the partnership has been the produced city food strategy which is adopted by the local state. Together with the support of the City council and the local health authority this adds to the legitimacy of the sustainable food system ideas and measures developed by the partnership and sends positive messages to public.

In addition, boundary work has allowed for consolidating and strengthening the city's sustainable food network. It has brought together a broad range of food-concerned actors, helped them to build shared values and lifestyles, reach mutual trust, agree on common informal rules and coordinate their actions. Regardless the common grounds and guidance that the partnership provides, its members carry out their activities in a flexible manner, there are no legal obligations and formal rules.

The holistic nature of the partnership poses also some barriers to reach its sustainability goals. To a lesser extent this is a challenge for its internal management as members are enthusiastic and devoted but in particular it concerns establishing external links and gaining external support. For instance, it is hard to gain support from the official agricultural knowledge system institutions and attract funding because the partnership is so multi-purpose.

The contrasting case of Biogas network in Latvia illustrates the controversies involved in negotiating meanings of sustainability and its various dimensions, and some unintended results (or failures) of boundary work. One of the principal needs driving boundary work in this LINSA was to arrive at societally acceptable and sustainable localised solutions of biogas production.

Biogas production in Latvia was politically (top-down) initiated with the arguments of enhancing energy and agricultural sustainability. It was aimed at renewable energy production, relevant in the situation of increasing fossil fuel use, energy dependence, farmers' low income and unutilised agricultural waste. However, initial boundary work and objects have been ineffective to align biogas producers with these goals and many of them, especially landless investors, have caught up the economic dimension of the initiative, which was promoted by such boundary objects as production quotas, public subsidies and guaranteed price. In the result many of biogas plants have been developed primarily as business projects for profit ignoring ecological and social sustainability.

The public image of biogas production has deteriorated and prioritizing business interests provoked protests among concerned farmers and scientists who insisted on the revision of the political, regulatory and controlling framework of biogas production to readjust it to sustainability criteria. Sustainability of biogas production as a boundary object has become an explicit object of discussions among LINSA 
members themselves. The boundary work performed to reach sustainable local solutions of biogas production involved three groups of actors: landless investors, local farmers-biogas producers, and biogas researchers. All were interested in localised technological solutions, but not all in sustainability concerns. Both farmers and researchers promote boundary work, but the group that stands apart is landless investors.

Boundary objects were formed of specific technologies of biogas production, either borrowed from abroad, or developed through own experimentation, or proposed by researchers. Connection of actors and negotiation of technologies took several forms: encounters (between farmers and technology providers, peer to peer exchanges among producers), practice-based negotiations (site visits, demonstrations, training seminars), specific work (joint experimentation with researchers). The boundary objects in this case are specific rather than general, and they constantly evolve reflecting new opportunities and new challenges. Recent legitimacy crisis in biogas production has prompted an initiative which can be labelled specific work to involve landless investors in a dialogue. However, they were not interested.

In this LINSA the boundary objects follow a trajectory from being specific and multiple to a new one, general and in acute need of reconciliation. Boundary work has been successful as practice-based activities and encounters around the specific boundary objects, but to a lesser extent as specific work (a dialogue meeting, commissioned research, negotiations) on the more general idea of biogas production as a sustainable endeavour. Despite the fact that the LINSA agrees about the necessity of local sustainable solutions, there is continued disagreement on different aspects of sustainability and no common prescriptive practices have been developed. Boundary work has not reduced the controversial impact of biogas production practices on environmental and social sustainability. Failure in better alignment of the actors can be attributed to the insufficient boundary work that would manage their considerable diversity, individualistic approaches and social distance between them and that would encourage incorporation of public interests of sustainability. One may also argue that the existence of powerful economic and political interests at play has obstructed the adaptive course of sustainability definition.

The two cases of boundary work and objects in addressing sustainability showed their co-development, albeit along differing trajectories. The difference in outcomes was greatly influenced by the inclusiveness/exclusiveness of the vision, the presence of power imbalances, and diversity or homogeneity of actors.

\section{Discussion and conclusion}

In this paper we explored the role of boundary work and boundary objects in agricultural and rural development networks. We have presented and discussed in depth several examples to illustrate how actors in LINSA learn and innovate jointly for sustainability, crossing different social, institutional, and conceptual boundaries. Focusing on the role of boundary work and objects has helped to understand how complex learning and innovation networks function, how stakeholders negotiate sustainability, coproduce innovation and learn for the future.

\subsection{Multiple expressions of boundary work are dynamically emerging}

The discussed LINSA demonstrate that boundary work fulfils multiple functions to achieve the network goals: it promotes learning processes and new knowledge, strengthens the network's internal 
structures, involves new supporters, and stimulates network ideas and the evolvement of the network's innovation. To foster alignment and cooperation, LINSA actors create and use boundary objects that represent the meaning of the negotiated idea for both themselves and the actors whose cooperation is desired. Boundary work and the evolvement of boundary objects are interrelated. Addressing different types of goals and actors necessitate application of different types of boundary work and boundary objects.

SOLINSA research confirmed the existence of several forms of boundary work used by LINSA to advance their development and socio-technical transformations. Following Wenger's (2000) typology, we identified encounters, boundary practices, peripheral work and specific work. We found that In LINSA these kinds of boundary work have additional traits, and involve specific constellations of actors, depending on the desired outcome and the stage in network evolution. Foremost, we note the evolvement of boundary work types over time.

Boundary work starts as encounters and the study confirmed the great variety of encounters: meetings, workshops, visits, seminars, etc. Encountering by doing proves to be efficient way of boundary bridging. This often happens during field days, demonstration events, study visits and other forms of practical learning. LINSA achieve more in terms of knowledge co-creation, concerted practices and network sustainability if practical encounters are organised regularly. Peripheral boundary work proved relevant in helping LINSA to build links with consumers, the like-minded civic groups and policy makers and to educate population about sustainability issues, especially if LINSA is value based. This kind of boundary work often takes the shape of cultural activities and public events, e.g. festivals, fairs, food events, science cafes, etc. Special boundary work was observed in many LINSA and may take a form of targeted research or demonstration projects, negotiations with authorities, development of a policy paper, a certification, etc.

Another aspect of boundary work is the diversity of actors; in each LINSA there is a specific constellation of actors involved depending on the issues at hand, these involve actors from the social-economic sphere, civic, knowledge and policy spheres; no case is the same. LINSA exhibit a particular strength in establishing links between peer-farmers, the farmers, researchers and advisors, agricultural community, civic groups and policy makers. Successful boundary work provides important gains for the network: shared meanings, improved practices, new supporters, visibility, and evolvement of structures and governance. Outcomes of boundary work can be differentiated as prescriptive or flexible, where the former means that all actors undertake to implement the results of boundary work in the same way, and latter means that actors do not commit themselves to carrying out identical but concerted set of actions. This points to the different degrees of coordination of activities in networks.

\subsection{Boundary objects take different shapes and can be broad or specific}

The data on the boundary objects used by LINSA confirms that they are physically and conceptually varied objects embedded in the specific contexts in which the LINSA operate. Empirically grounded types of boundary objects identified by our research are:

- Ideas, values, visions.

- Strategic papers, policy documents.

- Codes of practice, certification systems.

- Specific production methods, techniques. 
- Public events (meetings, festivals, forums etc.). This kind of boundary objects is blurred with boundary interaction, but it still has its distinctive objectivation and spatial form of communicative action.

- Production and marketing infrastructure.

Within and apart of these types there is a still greater variety of boundary objects to solve specific learning, innovation and transition to sustainability needs. Boundary objects simultaneously are shared cognitive structures (negotiated meanings) and tangible material things, objects, artefacts and reifications that embody these meanings (a leaflet of an organisation, a manual of a code of practice or a learning video for a specific production method). The convertibility of cognitive and material sides of boundary objects, the translation of ideas into material things consolidates the negotiated shared knowledge, extends its durability, and fosters more effective communication of LINSA ideas and practices internally and externally. Once agreed, boundary objects are a powerful tool in external communication to promote LINSA ideas. The range of boundary objects is broad and evolves with network development, thus our study echoes the conclusions of Clark et al (2011) that context is the key factor in boundary work success.

We also noted two broader types of boundary objects: general and specific, related to the stage in the development of the network, as well as various forms of boundary objects - ideas, documents, codes of practice, events, methods, and infrastructure. It must be noted that with the help of various information and communication technologies, boundary interactions, work and objects are increasingly virtual.

We have also demonstrated some network outcomes of boundary work, and the applicability of boundary work and boundary objects concepts to analysing multi-stakeholders interactions in selforganising networks. A LINSA is a particular network as it assembles not only farmers aiming at improving their practice (be it in terms of technology, marketing or organisation), but many different actors, as showed in the presented cases. In addition, a LINSA strongly focuses on the process of learning, i.e. negotiation and reflection among its members, aimed at renovation of existing practices or introducing new solutions. Finally, learning and innovations are targeted towards increasing sustainability, thus the practice of a LINSA is value-laden. Accordingly, LINSA has to provide the space to negotiate these three outcomes: learning, innovation, and sustainability. We have shown that for each, boundary objects and boundary work have particular requirements (see Figure 1).

[Figure 1. Requirements of boundary objects in LINSA: aspects boundary work has to bridge]

With regard to sustainability, boundary work needs to accommodate different attitudes and practices of sustainability; with regard to learning, the boundary objects used need to enable negotiation between stakeholder groups representing various knowledge cultures (e.g. practitioners and researchers), various attitudes towards learning outcomes /mistakes, and various learning forms; with regard to innovation, boundary work is relevant to negotiate between progressive and conservative parts of a LINSA, between LINSA members and potential supporters, and to adjust initial goals when they have been achieved and/or new opportunities are identified.

While most of these functions regard the internal organization of the network, there is a need for additional boundary work between the LINSA and the outside world. Reaching the relevant actors beyond the limits of the LINSA is crucial if innovation is aimed at inducing broader change.

Boundary work, objects and their connection are dynamic. Once proposed, negotiated and established, boundary objects remain open for further transformations. Many cases witness a certain sequence of 
boundary work and boundary objects that mirrors the development stages and related particular needs of the network. Supposedly, each of the further steps benefits from or is constrained by the knowledge already accumulated into the network's artefacts. There is certain correspondence between goals of boundary work, the kinds of boundary work employed and the boundary objects developing in the process. For instance, institutionalisation goals often show a pattern of encounters and specific work types of boundary work, and use highly specific boundary objects relying on scientific knowledge. Conversely, practice-based connections tend to be forged in learning activities, and also in dissemination of incremental innovation. This needs to be explored in further research.

\subsection{Boundary work needs to be carefully considered and facilitated}

Boundary interactions are not equally intensive among all network members; there are central and peripheral actors. Those interactions are facilitated by leaders (driving actors), individuals or entire organisations. As LINSA include complex constellations of stakeholders, boundary work can be potentially initiated by a range of driving actors. Often they are actors with multiple structural positions and influential personalities, whose personal and institutional traits are preconditions for engaging with LINSA in joint learning and innovation for sustainability in a range of roles - networker, facilitator, participatory researcher, boundary person, or specialist expert. These actors may be termed transition partners - to emphasize the multiplicity of their context-specific role (Moschitz et al 2014). As boundary work develops from one kind to another, its driving actors may change as well.

Our study suggests that boundary practices not necessarily stem from formal assignments of individuals and organisations, for example - corporative responsibilities of advisory service. These roles are rather attributed, negotiated and agreed among network partners and are based on their merit, trustful relations and committed engagement in practical interactions. Therefore boundary persons are often trusted researchers, civic activists and farmers who are dedicated to LINSA objectives and inspire other participants to share knowledge.

The multiple requirements that boundary objects need to fulfil for LINSA to function efficiently call for a careful consideration and facilitation of boundary work. As the results indicate, boundary objects can emerge from interaction, and, in line with earlier findings by Klerkx et al. (2012), they can be created purposefully. In both cases, strategic facilitation of boundary work will help an effective functioning of a LINSA. Schneider et al. (2009) emphasize the need to respect the structures in which the different actors usually work in order to achieve a successful engagement in boundary work across organisations. To support boundary work in LINSA it is thus necessary to carefully consider the backgrounds of different members. Boundary work will need the more attentive facilitation the more heterogeneous the members are, also to make effective use of heterogeneity.

However, one also needs to realise the limitations of boundary objects: they do not necessarily connect all the different life worlds represented in LINSA, there can be excluded actors or backsliders (resembling findings by Klerkx et al., 2012). This is partly related to the next limitation of boundary objects, i.e., in many cases they are issue specific and not relevant to every member, contested and variously prioritised depending on needs and priorities. Not all actors equally participate in their construction (typically LINSA leaders and strategic partners are more active). Boundary objects can be poorly distributed or inaccessible to all members. They cease to exist or turn into another boundary objects when the original learning need is satisfied. Boundary objects are not a universal remedy for LINSA problems but pragmatic entities to be co-constructed in order to solve learning and innovation issues. 
From facilitation and innovation support perspective, boundary work can be used as an instrument for LINSA transition towards sustainability, and it can be done according to two different logics. One logic is to concentrate on a specific boundary objects in LINSA, develop them through specifically targeted boundary interactions (e.g. development projects) driven by active boundary spanning individuals or organisations. Such an intervention would lead to fast learning and dissemination of novel practices, and stimulate radical innovations through establishing prescriptive codes and methods. However, the impact of such boundary work may be limited to narrow groups of stakeholders. The other logic is based on broader range of driving actors, uses of shared network resources, and boundary work that is embedded in different network practices and gradually develops and refines many different boundary objects responding to network diversity and scope of innovation. This kind of boundary work may produce a slower transition towards sustainability, yet the outcomes may be more durable.

Our examples have shown that boundary work supports also reflection in LINSA, as meanings of learning, innovation and sustainability are continuously negotiated and accepted as its goals. Through continued boundary work, reflection becomes a defining feature for LINSA. Facilitation is again needed to help this reflection while producing innovation. Researchers can take the role of facilitators who organize boundary work, meeting spaces and even suggest boundary objects. Yet, our work with LINSA showed that researchers need to be careful not to conflate roles. Within LINSA they can become part of the network, thus engage themselves in boundary work beyond mere facilitation of this process, as described also by Huzzard, Ahlberg, and Ekmann (2012). Reflectivity of LINSA then involves reflective researchers who facilitate boundary work of LINSA members to co-produce outcomes in learning, innovation and sustainability.

\section{References}

Bruckmeier, K., and H. Tovey. 2008. "Knowledge in Sustainable Rural Development: From Forms of Knowledge to Knowledge Processes." Sociologia Ruralis 48 (3): 313-329.

Brunori, G., D. Barjolle, A.-C. Dockes, S. Helmle, J. Ingram, L. Klerkx, H. Moshitz, G. Nemes, and T. Tisenkopfs. 2013. "CAP Reform and Innovation: The Role of Learning and Innovation Networks." Eurochoices 12 (2): 27-33.

Clark, W. C., T. P. Tomich, M. van Noordwijk, D. Guston, D. Catacutan, N. M. Dickson, and El. McNie. 2011. "Boundary Work for Sustainable Development: Natural Resource Management at the Consultative Group on International Agricultural Research (CGIAR)." Proceedings of the National Academy of Sciences. http://www.pnas.org/content/early/2011/08/11/0900231108.full.pdf+html .

Curry, N., and J. Kirwan. 2014. "The Role of Tacit Knowledge in Developing Networks for Sustainable Agriculture." Sociologia Ruralis. Article first published online: 27 APR 2014, DOI: 10.1111/soru.12048, 121

Gieryn, T. F. 1983. "Boundary-work and the demarcation of science from non-science: strains and interests in professional ideologies of scientists." American Sociological Review 48 (6): 781-795.

Guston, D. H. 2001. "Boundary Organizations in Environmental Policy and Science." Science Technology And Human Values 26 (4): 399-408. 
Hermans, F., I. Horlings, P.J. Beers, and H. Mommaas. 2010. "The Contested Redefinition of a Sustainable Countryside: Revisiting Frouws' Rurality Discourses." Sociologia Ruralis 50: 46-63.

Huzzard, T., B.M. Ahlberg, and M. Ekmann. 2012. "Constructing Interorganizational Collaboration. The Action Researcher as Boundary Subject." Action Research 8 (3): 293-314.

Klerkx, L., S. van Bommel, B. BO, H. Holster, J. V. Zwartkruis, and N. Aarts. 2012. "Design Process Outputs as Boundary Objects in Agricultural Innovation Projects: Functions and Limitations." Agricultural Systems 113: 39-49.

Klerkx, L., and C. Leeuwis. 2009. "The Emergence and Embedding of Innovation Brokers at Different Innovation System Levels: Insights from the Dutch Agricultural Sector." Technological Forecasting and Social Change 76: 849-860.

Klerkx, L., B van Mierlo, and C. Leeuwis. 2012. "Evolution of Systems Approaches to Agricultural Innovation: Concepts, Analysis and Interventions." In Farming Systems Research into the 21st Century: The New Dynamic, edited by I. Darnhofer, D.Gibbon, and B. Dedieu, 457-483. Springer Netherlands.

Knickel, K., G. Brunori, S. Rand, and J. Proost. 2009. "Towards a Better Conceptual Framework for Innovation Processes in Agriculture and Rural Development: From Linear Models to Systemic Approaches." Journal of Agricultural Education and Extension 15 (2): 131-146.

Koutsouris, A. 2008. "Innovating Towards Sustainable Agriculture: A Greek Case Study." The Journal of Agricultural Education and Extension 14: 203-215.

Lave, J., and E. Wenger. 1991. Situated Learning: Legitimate Peripheral Participation. Cambridge University Press.

Leeuwis, C., and N. Aarts. 2011. "Rethinking Communication in Innovation Processes: Creating Space for Change in Complex Systems." The Journal of Agricultural Education and Extension 17: 21 - 36.

Mollinga, P.P. 2010. Boundary Work and the Complexity of Natural Resources Management. https://dl.sciencesocieties.org/publications/cs/pdfs/50/Supplement 1/S-1

Moore, K. 1996. "Organizing Integrity: American Science and the Creation of Public Interest Organizations, 1955-1975." American Journal of Sociology 101 (6): 1592-1562.

Moschitz, H., T. Tisenkopfs, G. Brunori, R. Home, I. Kunda, and S. Sumane (2014) Final Report on the SOLINSA Project. Deliverable N8.2.

Oreszczyn, S., A. Lane, and S. Carr. 2010. "The Role of Networks of Practice and Webs of Influencers on Farmers' Engagement with and Learning about Agricultural Innovations." Journal of Rural Studies 26: 404-417.

Renting, H., H. Oostindie, C. Laurent, G. Brunori, D. Barjolle, and A. M. Jervell. 2008. "Multifunctionality of Agricultural Activities, Changing Rural Identities and New Institutional Arrangements." International Journal of Agricultural Resources, Governance and Ecology 7 (4-5): 361-385.

Ring, J. K., A. M. Peredo and J. J. Chrisman. 2010. "Business Networks and Economic Development in Rural Communities in the United States." Entrepreneurship Theory and Practice 34 (1): 171-195. 
Santos, B., J. A. Nunes, and M. P. Meneses. 2007. "Opening up the Canon of Knowledge and Recognition of Difference." In Another Knowledge is Possible: Beyond Northern Epistemologies, edited by B. S. Santos, London: Verso. http://www.boaventuradesousasantos.pt/media/Introduction(3).pdf

Schneider, F., P. Fry, T. Ledermann, and S. Rist. 2009. "Social Learning Processes in Swiss Soil Protection-The 'From Farmer - To Farmer' Project." Human Ecology 37 (4): 475-489.

Star S.L., and J. R. Griesemer. 1989. "Institutional Ecology, 'Translations' and Boundary Objects: Amateurs and Professionals in Berkeley's Museum of Vertebrate Zoology." Social Studies of Science 19 (3): 387-420.

Tisenkopfs, T., I. Kunda, and S. Šūmane. 2014. "Learning as Issue Framing in Agricultural Innovation Networks." The Journal of Agricultural Education and Extension 20 (3): 1 - 18.

Wenger, E. 2000. “Communities of Practice and Social Learning Systems.” Organization 7 (2): 225-246. 
Table 1. Boundary work manifestations in LINSA depending on boundary work focus

\begin{tabular}{|c|c|c|c|c|}
\hline 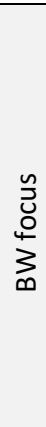 & $\begin{array}{r}\text { BW } \\
\text { Manifes- } \\
\text { tations } \\
\text { LINSA and } \\
\text { country }\end{array}$ & $\begin{array}{l}\text { Key actors in boundary } \\
\text { work: } \\
\text { Farmers } \\
\text { Consumers } \\
\text { Advisors } \\
\text { Researchers } \\
\text { Civic groups } \\
\text { Professional associations } \\
\text { SMEs } \\
\text { Policy makers } \\
\text { Local authorities }\end{array}$ & $\begin{array}{l}\text { Main forms of boundary } \\
\text { work: } \\
\text { Encounters } \\
\text { Practices } \\
\text { Peripheries } \\
\text { Specific work }\end{array}$ & $\begin{array}{l}\text { Main outcomes of } \\
\text { boundary work }\end{array}$ \\
\hline \multirow{2}{*}{ 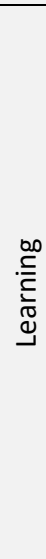 } & $\begin{array}{l}\text { Fruit } \\
\text { growing } \\
\text { network, } \\
\text { Latvia }\end{array}$ & $\begin{array}{l}\text { Farmers } \\
\text { Researchers } \\
\text { Professional associations }\end{array}$ & $\begin{array}{l}\text { Encounters (field days, } \\
\text { seminars, visits) } \\
\text { Peripheries (Apple } \\
\text { Festival, Cherry Days) } \\
\text { Specific work (research } \\
\text { and demonstration } \\
\text { projects) }\end{array}$ & $\begin{array}{l}\text { Improved practices in } \\
\text { integrated fruit-growing }\end{array}$ \\
\hline & $\begin{array}{l}\text { Charter of } \\
\text { Good } \\
\text { Practices, } \\
\text { France }\end{array}$ & $\begin{array}{l}\text { Farmers } \\
\text { Advisors } \\
\text { Researchers } \\
\text { Professional associations }\end{array}$ & $\begin{array}{l}\text { Encounters (informal } \\
\text { interviews, meetings) } \\
\text { Boundary practices (joint } \\
\text { consultations at local } \\
\text { regional and national } \\
\text { level, reviewing of the } \\
\text { Charter) }\end{array}$ & $\begin{array}{l}\text { Development and } \\
\text { adoption of sustainable } \\
\text { practices in cattle } \\
\text { production }\end{array}$ \\
\hline \multirow[b]{2}{*}{ 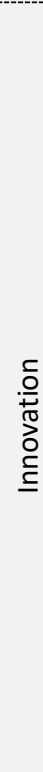 } & $\begin{array}{l}\text { Cooperative } \\
\text { of health } \\
\text { care farms } \\
\text { "Boer en } \\
\text { Zorg", The } \\
\text { Netherlands }\end{array}$ & $\begin{array}{l}\text { Farmers } \\
\text { Policy makers } \\
\text { Local authorities } \\
\text { Professional associations } \\
\text { Researchers } \\
\text { Advisors }\end{array}$ & $\begin{array}{l}\text { Encounters (meetings, } \\
\text { visits, seminars) } \\
\text { Boundary practices } \\
\text { (cooperative maintaining } \\
\text { links with local authorities) } \\
\text { Specific work } \\
\text { (commissioned research } \\
\text { to confirm value) }\end{array}$ & $\begin{array}{l}\text { Development of care } \\
\text { farming as a service } \\
\text { between two } \\
\text { institutional systems }\end{array}$ \\
\hline & $\begin{array}{l}\text { Association } \\
\text { Crisoperla, } \\
\text { Italy }\end{array}$ & $\begin{array}{l}\text { Farmers, } \\
\text { Consumers } \\
\text { Advisors } \\
\text { Local authorities } \\
\text { Professional associations } \\
\text { Civic groups } \\
\text { SMEs } \\
\text { Researchers }\end{array}$ & $\begin{array}{l}\text { Encounters (meetings, } \\
\text { visits, seminars) } \\
\text { Peripheries (workshops, } \\
\text { drafting of policy } \\
\text { proposals, fairs, seeking } \\
\text { links with new civic } \\
\text { groups) } \\
\text { Boundary practices } \\
\text { (participation in regional } \\
\text { and national associations) } \\
\text { Specific work (developing } \\
\text { a code of practice) }\end{array}$ & $\begin{array}{l}\text { Redefined meaning and } \\
\text { practices of organic } \\
\text { farming, involving not } \\
\text { only technical, but social, } \\
\text { ethical and political } \\
\text { aspects. }\end{array}$ \\
\hline 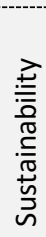 & $\begin{array}{l}\text { Brighton } \\
\text { and Hove } \\
\text { Food } \\
\text { Partnership, } \\
\text { UK }\end{array}$ & $\begin{array}{l}\text { Civic groups } \\
\text { Consumers } \\
\text { SMEs } \\
\text { Local authorities }\end{array}$ & $\begin{array}{l}\text { Encounters (partnership } \\
\text { development meetings) } \\
\text { Peripheries (newsletter, } \\
\text { publicity activities) } \\
\text { Specific work (group } \\
\text { projects, college course) }\end{array}$ & $\begin{array}{l}\text { Redefined } \\
\text { understanding of } \\
\text { sustainable well-being in } \\
\text { the city; good practices } \\
\text { conveyed widely }\end{array}$ \\
\hline
\end{tabular}




\begin{tabular}{|l|l|l|l|l|}
\hline $\begin{array}{l}\text { Biogas } \\
\text { network, } \\
\text { Latvia }\end{array}$ & $\begin{array}{l}\text { Researchers } \\
\text { Farmers } \\
\text { SMEs }\end{array}$ & $\begin{array}{l}\text { Encounters ( field days, } \\
\text { informal meetings) } \\
\text { Specific work } \\
\text { (commissioned research, } \\
\text { demonstration projects) }\end{array}$ & $\begin{array}{l}\text { Continued disagreement } \\
\text { on different aspects of } \\
\text { sustainability } \\
\text { (environmental, social, } \\
\text { economic) }\end{array}$ \\
\cline { 2 - 5 } & & & & \\
\hline
\end{tabular}

Figure 1. Requirements of boundary objects in LINSA: aspects boundary work has to bridge

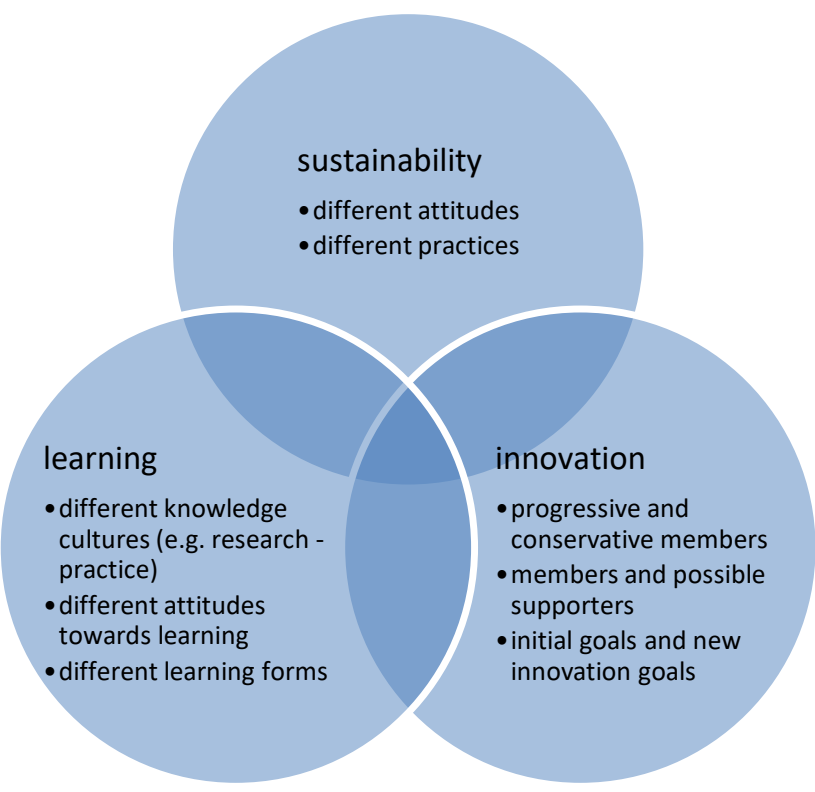

